\title{
STUDY ALIRAN DAYA (LOAD FLOW) PADA SISTEM DISTRIBUSI TENAGA LISTRIK GEDUNG PASCA SARJANA UNIVERSITAS BHAYANGKARA SURABAYA
}

\author{
Agus Kiswantono', Darul Ilmi Firmansyah² \\ (1)(2) Universitas Bhayangkara Surabaya, Indonesia \\ kiswantono@gmail.com
}

\begin{abstract}
Abstrak.
Studi aliran beban dimaksudkan untuk memperoleh informasi mengenai aliran daya atau tegangan pada suatu jaringan sistem tenaga listrik. Informasi ini sangat dibutuhkan untuk mengevaluasi unjuk kerja sistem tenaga. Permasalahan aliran daya mencakup perhitungan aliran dan tegangan sistem pada terminal atau bus tertentu. penelitian evaluatif dengan menggunakan metode penelitian operation research/action research, Manfaat studi aliran daya ini yaitu, untuk mengetahui tegangan pada setiap simpul yang ada pada sistem, untuk mengetahui semua peralatan apakah memenuhi batas - batas yang ditentukan untuk meyalurkan daya yang diinginkan, dan untuk memperoleh kondisi mula pada perencanaan sistem yang baru. Studi study aliran beban ini mengambil contoh pada implementasi sistem tenaga listrik di lembaga pendidikan Universitas Bhayangkara Surabaya, dengan karakteristik beban terpusat (lumped load), jaringan sistem distribusi tenaga listrik berupa jaringan radial dan sumber tegangan berasal dari saluran menengah PLN $20 \mathrm{kV}$ menuju ke titik - titik beban. Dari hasil perhitungan aliran daya berbantuan program ETAP (Electrical Transient Analyzer Program) dapat disimpulkan bahwa sistem jaringan listrik sudah baik. Hasil yang diperoleh adalah Circuit breaker pada CB4 mengalami overload dan pada bus 24, bus 4 dan bus 6 mengalami undervoltage. Sedangkan aliran daya masih memenuhi standar menurut hasil Text Report pada ETAP.
\end{abstract}

Kata kunci : study beban, ETAP, PLN $20 \mathrm{kV}$

\begin{abstract}
Load flow study is intended to obtain information about the flow of power or voltage in an electric power system network. This information is needed to evaluate the performance of the power system. Power flow problems involve calculating the system flow and voltage at a particular terminal or bus. evaluative research using the research method of operation research / action research, The benefits of this power flow study are to find out the voltage at each node in the system, to find out whether all the equipment meets the limits specified to deliver the desired power, and to obtain initial conditions in the new system planning. This load flow study study takes an example of the implementation of the electric power system at the Bhayangkara University of Surabaya educational institutions, with the characteristics of a centralized load (lumped load), the electricity distribution system network in the form of a radial network and a voltage source from the $20 \mathrm{kV}$ PLN intermediate line to the point - load point. From the calculation of power flow assisted by the ETAP (Electrical Transient Analyzer Program) program, it can be concluded that the electrical network system is good. The results obtained are that the circuit breaker on CB4 has an overload and on bus 24, bus 4 and bus 6 experience an undervoltage. Meanwhile, the power flow still meets the standards according to the results of the Text Report on ETAP.
\end{abstract}

Keywords: load study, ETAP, PLN 20kV

\section{PENDAHULUAN}

Dalam dunia pendidikan, listrik sudah menjadi kebutuhan primer sebagai sumber energi utama untuk mensuplai semua kebutuhan listrik yang ada di dunia pendidikan, energi listrik diambil dari pasokan listrik Perusahaan Listrik Negara (PLN). Seiring berjalannya waktu, bagian Texturizing pun terus melakukan pengembangan khususnya di sektor pembangunan, yang berarti bertambah pula jumlah beban yang harus ditanggung. Akibatnya, desain konfigurasi awal dari sistem jaringan kelistrikan yang awalnya baik dan mampu melayani beban dengan baik, bisa jadi menjadi tidak 
sesuai lagi dengan keadaan pembebanan saat ini. Untuk itu, perlu dilakukan study aliran daya untuk mengetahui kondisi secara keseluruhan dari sistem tenaga listrik pada bagian Texturizing di Universitas Bhayangkara Surabaya saat ini.

Study aliran daya dalam sistem tenaga listrik merupakan study yang mengungkapkan kinerja suatu sistem tenaga listrik dan aliran daya (nyata dan reaktif) untuk keadaan tertentu ketika sistem bekerja. Hasil utama dari aliran daya adalah besar dan sudut fasa tegangan pada setiap saluran (bus), daya nyata dan daya reaktif yang ada pada setiap saluran. Hasil study aliran daya dapat digunakan untuk mengetahui besarnya losses (rugi daya dan tegangan), alokasi daya reaktif dan kemampuan sistem untuk memenuhi pertumbuhan beban.

Perhitungan aliran daya untuk sistem tenaga listrik pada bagian Texturizing di Universitas Bhayangkara Surabaya secara manual akan sangat rumit, oleh sebab itu dalam penelitian ini digunakan software komputer untuk mempermudah dan mempercepat dalam proses perhitungan aliran daya. ETAP (Electrical Transient Analisis Program) Power Station merupakan salah satu software yang dapat digunakan untuk perhitungan aliran daya pada sistem tenaga listrik. Dengan menggunakan software ETAP Power Station 7.0 akan dapat mengstudy sistem tenaga listrik yang sangat luas (Agung, 2009 dalam Dhimas, 2014 : 2).

Penelitian ini bertujuan untuk mengetahui: 1) besar nilai aliran daya yang meliputi daya Constant yang ada pada bagian Texturizing di Universitas Bhayangkara Surabaya, 2) besar nilai rugi (losses) yang terdapat dalam sistem tenaga listrik pada bagian Texturizing di Universitas Bhayangkara Surabaya, 3) besar nilai tegangan pada setiap bus yang ada pada bagian Texturizing di Universitas Bhayangkara Surabaya.

\section{METODE PENELITIAN}

Dari segi desain dapat dijelaskan bahwa penelitian ini merupakan penelitian evaluatif dengan menggunakan metode penelitian operation research/action research, dan ekperimen dengan tingkat eksplanasi berupa deskriptif. Jadi peneliti akan mengambil data yang ada dilapangan baik pengukuran maupun kalkulasi study simulasi pada program bantu. Program akan memberikan laporan terkait dengan aliran daya sehingga peneliti dengan mudah mengetahui apakah sistem masih mampu mengalirkan daya dengan baik. Waktu penelitian ini dilaksanakan pada bulan Agustus 2018 bertempat di Universitas Bhayangkara Surabaya.

Pengumpulan data yang dilakukan dalam penelitian ini adalah :

\section{Observasi}

Observasi dilakukan di Universitas Bhayangkara Surabaya. Dalam observasi ini diperoleh berupa data transformator, data bus, data sistem pengaman, dan data beban yang terdapat di Universitas Bhayangkara Surabaya.

2. Studi pustaka

Studi pustaka yaitu informasi yang diperoleh dengan cara membaca, mencatat sistematis yang berkaitan dengan perhitungan aliran daya yang diperoleh dari sumber tertentu.

\section{Eksperimen}


Eksperimen ini menggunakan perngkat lunak (software) ETAP powerstaion 7.0. dalam mengstudy aliran daya. Data masukkan diperoleh dari hasil observasi yang dilakukan oleh peneliti.

\section{Study}

Mengstudy dan membahas data-data yang di dapat dari hasil penelitian. Study data dilakukan dengan metode perhitungan aliran daya yang terdapat dalam software ETAP powerstation 7.0.

Untuk metode study aliran daya, data-data yang telah diperoleh selanjutnya distudy mengunakan software ETAP power station 7.0. Dengan bantuan software ETAP power station 7.0. dapat mempermudah proses study aliran daya karena hasil dari study akurat dan sesuai dengan teori study yang sudah ada.

Study aliran daya listrik dengan software ETAP power station 7.0. berdasarkan pada single line diagram dan data-data masukkan dari hasil penelitian yang telah diketahui. Untuk menjalankan software ETAP power station 7.0. terlebih dahulu menggambar diagram segaris sistem kelistrikan Universitas Bhayangkara Surabaya. Setelah diagram segaris digambarkan pada setiap komponen dalam diagram segaris seperti sumber (power grid), transformator, bus, beban dan lain-lain diberi data masukkan sesuai karakteristik komponen-komponen tersebut. Jika data yang dimasukkan tidak benar maka software ETAP power station 7.0 tidak akan menjalankan perintah untuk mengstudy aliran daya (error). Setelah data yang dimasukkan lengkap dan benar selanjutnya dipilih metode aliran daya yang tersedia sebelum menjalankan program, pada penelitian ini dipilih metode Newton Raphson.

Dari study software ETAP power station 7.0 dapat dijadikan sebagai referensi kelistrikkan di Universitas Bhayangkara Surabaya. Hasil dari software ETAP power station 7.0. berupa laporan yang terdiri atas data masukkan dan laporan hasil dari perhitungan aliran daya yang dilakukan oleh program.

\section{HASIL DAN PEMBAHASAN}

\section{Klasifikasi Jaringan}

Berikut ini adalah klasifikasi jaringan kelistrikan yang ada di Universitas Bhayangkara Surabaya yaitu :

1. Menggunakan satu sumber tenaga listrik utama yaitu dari PLN dan penambahan daya Transformator $20 \mathrm{KV}$, sedangkan Gen.set sebagai sumber tenaga listrik cadangan dan hanya digunakan untuk penerangan ketika terjadi pemadaman listrik dari PLN.

2. Mempunyai satu swing bus (bus referensi)

3. Mempunyai satu load bus (bus beban). Pada bagian Texturizing, terdapat satu buah trafo yang berkapasitas $630 \mathrm{kVA}$.

4. Beban yang digunakan degan kharakteristik beban terpusat (lumped load)

5. Terdapat satu panel kapasitor bank sebagai penyuplai ke beberapa beban yang ada di Universitas Bhayangkara Surabaya. 
Seminar Nasional Penelitian dan Pengabdian kepada Masyarakat Universitas Sang Bumi Ruwa Jurai Tahun 2020

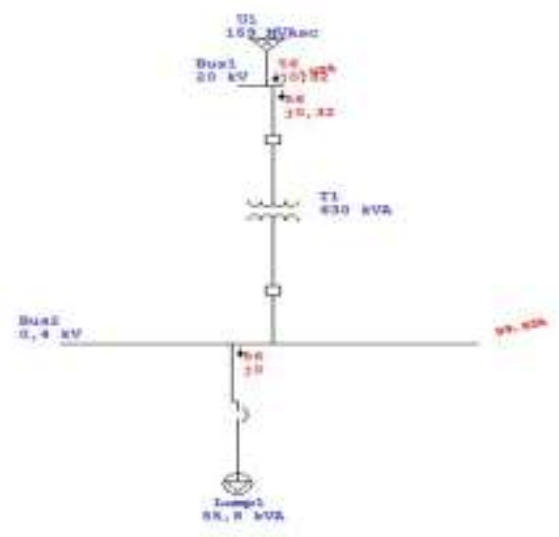

Gambar 1. Simulasi Load Flow Pada ETAP 7.0

\section{Study Aliran Daya Menggunakan Software ETAP 7.0}

Tabel 1. Data Besaran Daya

\begin{tabular}{|l|l|l|}
\hline Bus & Constant KVA & Constant Z (Kvar) \\
\hline Bus 1 & 57 & 3 \\
\hline
\end{tabular}

Tabel 1 berisi informasi tentang besaran daya pada beban yaitu daya constant KVA, daya constant Z. Besaran daya ini merupakan hasil perhitungan dari ETAP setelah semua data masukan dimasukkan pada single line diagram dan dieksekusi.

Tabel II. Hasil Critical Report

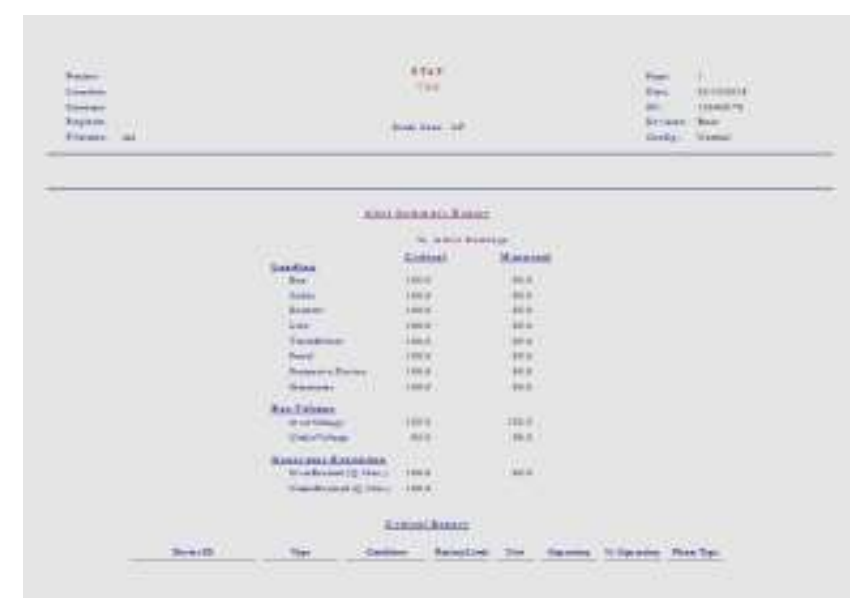

Tabel 2 memberikan informasi tentang nilai circuit breaker yang over load dan juga nilai - nilai bus yang memiliki nilai undervoltage pada tiap bus gambar 
Seminar Nasional Penelitian dan Pengabdian kepada Masyarakat Universitas Sang Bumi Ruwa Jurai Tahun 2020

Tabel III. Hasil Branch Losses Report

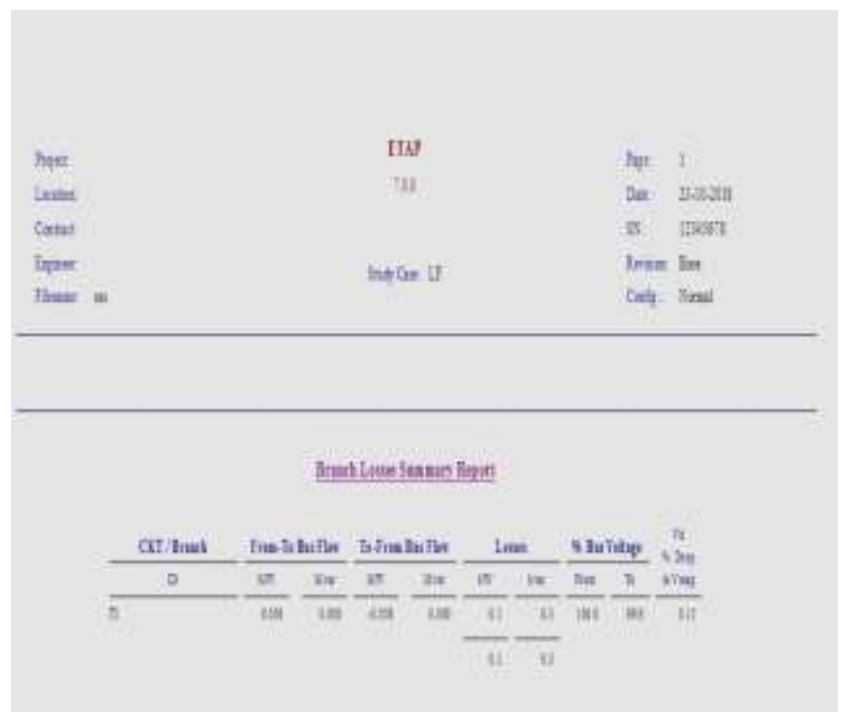

Tabel 3 berisi informasi tentang informasi mengenai rugi ( losses ) pada transformator dan pada tiap - tiap kabel dengan hasil sebagai berikut :

1. Tranformator 1 memiliki losses sebesar $0,1 \mathrm{KW}$ dan $0,3 \mathrm{Kvar}$

\section{Tabel IV. Hasil Unbalanced Load Flow Report}

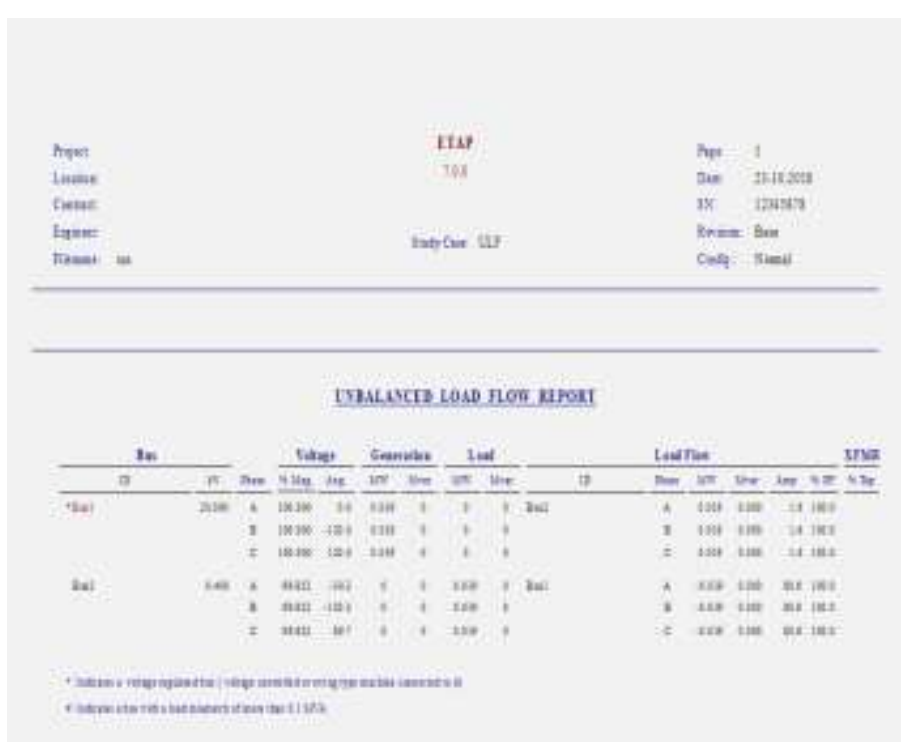

Tabel 4. memberikan informasi tentang nilai aliran daya tidak seimbang pada ETAP 7.0 dengan hasil sebagai berikut :

1. bus 1 memiliki generation sebesar $19 \mathrm{KVA}$ 
Seminar Nasional Penelitian dan Pengabdian kepada Masyarakat Universitas Sang Bumi Ruwa Jurai Tahun 2020

Tabel V Hasil Load Flow Report

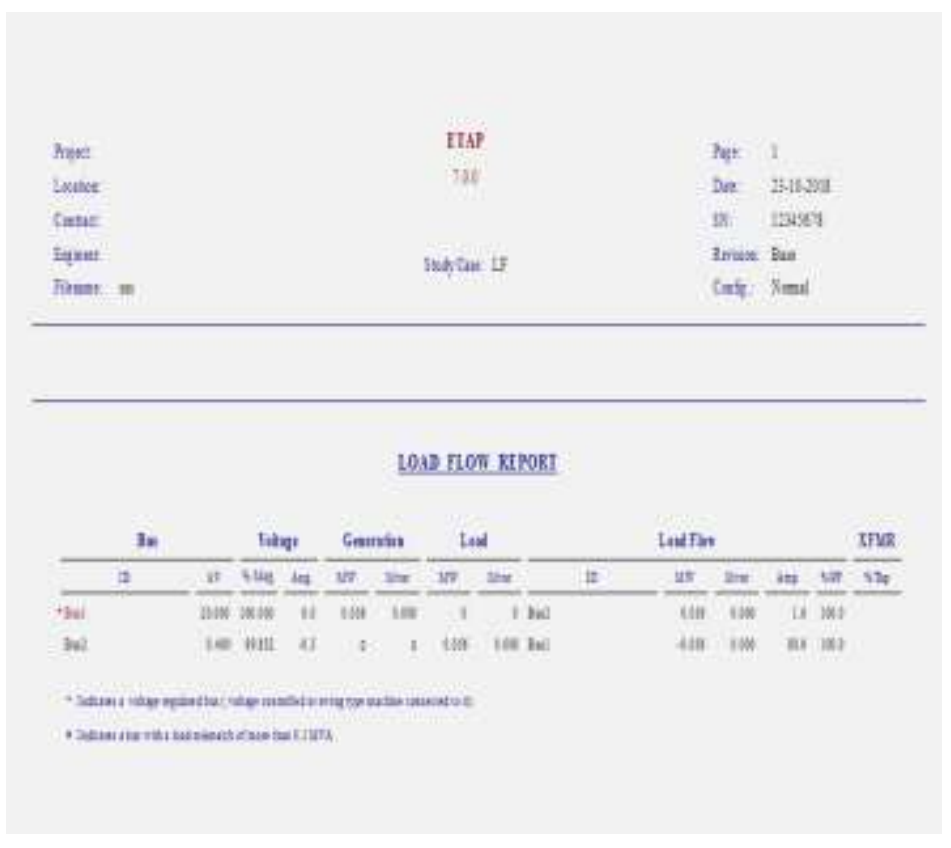

Tabel 5 memberikan informasi tentang nilai aliran daya tidak seimbang pada ETAP 7.0 dengan hasil sebagai berikut :

1. Bus 1 memiliki generation sebesar $56 \mathrm{KVA}$

Dari hasil study load flow pada jaringan listrik transformator distribusi $20 \mathrm{KV}$, dapat disimpulkan sebagai berikut :

1. Nilai daya constant KVA dan nilai daya konstant Kvar memiliki selisih yang masih terbilang standart dari perhitungan.

2. Pada transformator mengalami rugi ( losses ) sebesar $0,1 \mathrm{KW}$ dan $0,3 \mathrm{Kvar}$.

3. Pada analisa aliran daya tidak seimbang bus 1 dan bus 2 mengalami generation sebesar 19 KVA . Dan pada tiap - tiap bus mempunyai load flow dengan jumlah total sebesar 56 KVA

4. Pada analisa aliran daya seimbang bus 1 dan bus 2 mengalami generation sebesar 56 KVA. Dan pada tiap - tiap bus mempunyai load flow dengan jumlah total sebesar 56.
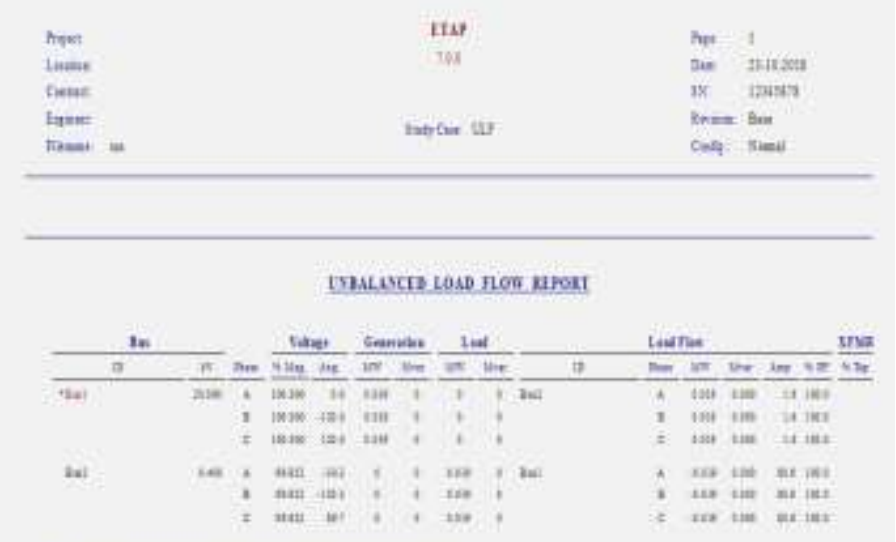


\section{KESIMPULAN}

Manfaat studi aliran daya ini yaitu, untuk mengetahui tegangan pada setiap simpul yang ada pada sistem, untuk mengetahui semua peralatan apakah memenuhi batas - batas yang ditentukan untuk meyalurkan daya yang diinginkan, dan untuk memperoleh kondisi mula pada perencanaan sistem yang baru. Studi study aliran beban ini mengambil contoh pada implementasi sistem tenaga listrik di lembaga pendidikan Universitas Bhayangkara Surabaya, dengan karakteristik beban terpusat (lumped load), jaringan sistem distribusi tenaga listrik berupa jaringan radial dan sumber tegangan berasal dari saluran menengah PLN $20 \mathrm{kV}$ menuju ke titik - titik beban. Dari hasil perhitungan aliran daya berbantuan program ETAP (Electrical Transient Analyzer Program) dapat disimpulkan bahwa sistem jaringan listrik sudah baik. Hasil yang diperoleh adalah Circuit breaker pada CB4 mengalami overload dan pada bus 24, bus 4 dan bus 6 mengalami undervoltage. Sedangkan aliran daya masih memenuhi standar menurut hasil Text Report pada ETAP.

\section{DAFTAR PUSTAKA}

Agung, H. (2009). Study Load Flow dalam Sistem Tenaga Listrik di PT. Sinar Sosro Ungaran. Skripsi. Semarang : Jurusan Teknik Elektro Universitas Negeri Semarang.

Arikunto, Suharsimi. (2010). Prosedur Penelitian. Jakarta : PT Asdi Mahasatya.

Dhimas, P. H. (2014). Pemanfaatan Software ETAP Power Station 7.0.0 untuk Mengstudy Aliran Daya Listrik di Gardu Induk Ungaran 150 kV. Skripsi. Semarang : Jurusan Teknik Elektro Universitas Negeri Semarang.

Ehendra's Blog. (2010). Proteksi Pada Sistem Tenaga Listrik. Online. Tersedia di http://ehendra.wordpress.com/stl-01/ diakses [4-9-2014].

Kadir, Abdul.(2006). Distribusi dan Utilisasi Tenaga Listrik, Jakarta : UI - Press.

Prabowo, H. (2007). Study Aliran Daya di Wilayah Kerja PT PLN (Persero) UPT Semarang. Skripsi. Semarang : Jurusan Teknik Elektro Universitas Negeri Semarang.

Sigit, A. P. (2015). Study Aliran Daya (Load Flow) dalam Sistem Tenaga Listrik Menggunakan Software ETAP Power Station 7.0.0 di PT. Kota Jati Furnindo Jepara. Skripsi. Semarang : Jurusan Teknik Elektro Universitas Negeri Semarang.

Sugiyono. (2010). Metode Penelitian Pendidikan, Bandung : CV. Alfabeta.

Sulasno. (1993). Study Sistem Tenaga Listrik, Semarang : Satya Wacana.

Stevenson, Jr. W. D. (1990). Study Sistem Tenaga Listrik, Jakarta : Erlangga.

Tobing, B. L. (2003). Peralatan Tegangan Tinggi, Jakarta : PT. Gramedia Pustaka. 
Seminar Nasional Penelitian dan Pengabdian kepada Masyarakat Universitas Sang Bumi Ruwa Jurai Tahun 2020

Unggul, D. K. (2011). Simulasi Aliran Daya pada Penyulang 2 Gardu Induk Rawalo dengan Menggunakan Software ETAP 7.0. Jurnal. Semarang : Jurusan Teknik Elektro Fakultas Teknik Universitas Diponegoro.

Zuhal. (1998). Dasar Teknik Tenaga Listrik dan Elektronika Daya, Jakarta : PT. Gramedia Pustaka Utama 